\title{
Bcl-2 Genes Regulate Noise-Induced Hearing Loss
}

\author{
Daisuke Yamashita, ${ }^{1-3}$ Shujiro B. Minami, ${ }^{1,2}$ Sho Kanzaki, ${ }^{2}$ Kaoru Ogawa, ${ }^{2}$ \\ and Josef M. Miller ${ }^{1,4 \star}$ \\ ${ }^{1}$ Kresge Hearing Research Institute, University of Michigan, Ann Arbor, Michigan \\ ${ }^{2}$ Department of Otolaryngology, Keio University Hospital, Tokyo, Japan \\ ${ }^{3}$ Department of Otolaryngology, National Tokyo Medical Center, Tokyo, Japan \\ ${ }^{4}$ Center for Hearing and Communication, Karolinska Institutet, Stockholm, Sweden
}

Proteins of the Bcl-2 family have been implicated in control of apoptotic pathways modulating neuronal cell death, including noise-induced hearing loss. In this study, we assessed the expressions of anti- and proapoptotic Bcl-2 genes, represented by $\mathrm{Bcl}-\mathrm{xL}$ and Bak following noise exposures, which yielded temporary threshold shift (TTS) or permanent threshold shift (PTS). Auditory brainstem responses (ABRs) were assessed at 4, 8, and $16 \mathrm{kHz}$ before exposure and on days 1, 3, 7, and 10 following exposure to $100 \mathrm{~dB}$ SPL, $4 \mathrm{kHz}$ OBN, $1 \mathrm{hr}$ (TTS) or $120 \mathrm{~dB}$ SPL, $4 \mathrm{kHz}$ OBN, $5 \mathrm{hr}$ (PTS). On day 10, subjects were euthanized. ABR thresholds increased following both exposures, fully recovered following the TTS exposure, and showed a $22.6 \mathrm{~dB}$ (4 $\mathrm{kHz}), 42.5 \mathrm{~dB}(8 \mathrm{kHz})$, and $44.9 \mathrm{~dB}(16 \mathrm{kHz})$ mean shift on day 10 following the PTS exposure. PTS was accompanied by outer hair cell loss progressing epically and basally from the $4-\mathrm{kHz}$ region. Additional animals were euthanized for immunohistochemical assessment. BcL-xL was robustly expressed in outer hair cells following TTS exposure, whereas Bak was expressed following PTS exposure. These results indicate an important role of the $\mathrm{Bcl}-2$ family proteins in regulating sensory cell survival or death following intense noise. $\mathrm{Bcl}-\mathrm{xL}$ plays an essential role in prevention of sensory cell death following TTS levels of noise, and PTS exposure provokes the expression of Bak and, with that, cell death. () 2007 Wiley-Liss, Inc.

Key words: inner ear; hearing; guinea pig; apoptosis; Bcl-xL; Bak

Apoptosis plays an important role in metabolic stress-induced neuronal cell death, including sensorineural cell death in the auditory system induced by intense noise exposure (Hu et al., 2002; Wang et al., 2003; Lang et al., 2006). Thus direct mechanical trauma induced by intense noise exposure may contribute to cochlear sensory cell death involving necrosis or apoptosis (Yang et al., 2004; Hu et al., 2006). Noise exposure also causes hearing loss and sensory cell death resulting from metabolically initiated changes, including formation of reactive oxygen species (ROS), reactive nitrogen species (RNS), and other free radical species (Ohlemiller et al., 2000; Van Campen et al., 2002; Coling et al., 2003; Ohinata et al., 2003; Yamashita et al., 2004a; Henderson et al., 2006). These free radicals may directly cause the destruction of cellular and subcellular elements and may also serve as signaling molecules to up-regulate genes responsible for cell survival and apoptotic cell death. Recent studies of morphological characteristics and biochemical events in sensorineural elements of the inner ear following noise exposure have indicated nuclear condensation, DNA fragmentation, cell shrinkage, and activation of endonucleases consistent with apoptotic processes underlying noise-induced hearing loss (NIHL) and driving hair cell and auditory nerve death (Nicotera et al., 2003; Yamashita et al., 2004b; Vicente-Torres and Schacht, 2006).

Many molecules have been identified as executing factors or key modulators in apoptosis. Among them, proteins of the Bcl-2 family principally control the mitochondrial-initiated apoptotic pathway (Adams and Cory, 1998; Tsujimoto and Shimizu, 2000a). Bcl-2 family members act upstream of caspase activation and serve as checkpoints in the regulation of apoptosis (Green and Kroemer, 2004). The Bcl-2 family includes two groups: antiapoptotic members include $\mathrm{Bcl}-2$ and $\mathrm{Bcl}-\mathrm{xL}$, and proapoptotic members include Bax and Bak. These proteins form homodimers, and the ratio of antiapoptotic to proapoptotic Bcl-2 family members within a cell determines cell survival or death following damaging stimuli (Ouyang and Giffard, 2004). Bcl-xL is localized primarily to the outer mitochondrial membrane, where it functions to inhibit the mitochondrial permeability and

Contract grant sponsor: NIDCD, NIH; Contract grant number: R01 DC004058; Contract grant sponsor: General Motors/United Automobile Workers Union; Contract grant sponsor: Ruth and Lynn Townsend Professorship of Communication Disorders.

^Correspondence to: Josef M. Miller, PhD, Kresge Hearing Research Institute, University of Michigan, 1301 E. Ann Street, Ann Arbor, MI 48109-0506. E-mail: josef@umich.edu

Received 23 May 2007; Revised 20 July 2007; Accepted 31 July 2007

Published online 17 October 2007 in Wiley InterScience (www. interscience.wiley.com). DOI: 10.1002/jnr.21533 
serves to modulate cytochrome $\mathrm{c}$ release, free radical production, and calcium accumulation. $\mathrm{Bcl}-\mathrm{xL}$ also blocks the effect of proapoptotic Bcl-2 family members by heterodimerization and regulation of the voltage-dependent anion channel on the outer membrane of mitochondria (Tsujimoto and Shimizu, 2000b) and the adenine nucleotide translocator on the inner mitochondria membrane (Vieira et al., 2000). Recent reports document the capacity of Bcl-xL to block cell death after cerebral ischemia (Asoh et al., 2002). Proapoptotic Bak is localized predominantly in the cytosol of normal cells and translocates to mitochondria after apoptotic stimulation. Bak promotes cytochrome $\mathrm{c}$ release from mitochondria, leading to activation of caspase- 9 and then caspase-3, which begins the degradation phase of apoptosis (Ganju and Eastman, 2002; Scorrano et al., 2003; Klee and Pimentel-Munoz, 2005).

In the auditory system, the localization of mRNAs of the Bcl-2 family proteins has been investigated in mouse embryos, in early postnatal development, and in adult mice (Ishii et al., 1996). Recent investigations have demonstrated a relationship between Bcl-2 family proteins and several cochlear disorders, such as increased sensitivity to neomycin-induced hearing loss (Cunningham et al., 2004), NIHL following sound conditioning (Niu et al., 2003), age-related hearing loss (Alam et al., 2001), and cisplatin-induced hair cell death (Alam et al., 2000).

NIHL may be divided into two categories: temporary threshold shift (TTS) and permanent threshold shift (PTS). The former is associated with little or no sensory cell death, the latter with clear loss of sensory cells. This allows us to question the relative role of $\mathrm{Bcl}-2$ genes in cells placed under extreme noise-induced metabolic stress sufficient to induce formation of free radicals; in one case, sensory cells recover and survive, whereas, in the other case, cell death follows. In this study, we investigated differences in the pathogenesis of TTS and PTS hearing loss by assessing the immunohistochemistry of Bcl-xL and Bak following exposure to sound levels that would produce TTS (cell survival) and PTS (cell death). We hypothesized that both genes would be expressed following these two stresses but that the balance of expression would differ significantly, with major expression of anti-apoptotic Bcl-xL in hair cells following exposure to TTS noise and proapoptotic Bak demonstrating major expression in hair cells following PTS exposure.

\section{MATERIALS AND METHODS}

\section{Animals}

Thirty-five pigmented guinea pigs (250-300 g; Elm Hill Breeding Labs, Chelmsford, MA) with a normal Preyer's reflex were used in this study. The experimental protocol was reviewed and approved by the Animal Care and Use Committee at the University of Michigan and conforms to the National Institutes of Health Guide for the care and use of laboratory animals.

\section{Noise Exposure}

Animals were exposed in pairs, in separate cages, to one-octave-band noise centered at $4 \mathrm{kHz}$, at $100 \mathrm{~dB}$ SPL for $1 \mathrm{hr}$ (TTS model) or at $120 \mathrm{~dB}$ SPL for $5 \mathrm{hr}$ (PTS model), in a ventilated sound-exposure chamber. The sound chamber was fitted with speakers (model $2450 \mathrm{H}, \mathrm{JBL}$ ) driven by a noise generator (ME $60 \mu$ graphic equalizer; Rane) and power amplifier (HCA-1000 high current power amplifier; Parasound Products). Sound levels were calibrated (Bruel and Kjaer Instruments, type 2203 precision sound level meter, type 4134 microphone) at multiple locations within the sound chamber to ensure uniformity of the stimulus and analyzed by using a fast Fourier transform network analyzer with a linear scale. The stimulus intensity varied by a maximum of $3 \mathrm{~dB}$ across measured sites within the exposure chamber. During noise exposure, noise levels were monitored with a sound level meter, a preamplifier, and a condenser microphone. The microphone was positioned within the cage at the approximate level of the animal's head.

\section{Auditory Brainstem Responses}

Auditory evoked brainstem responses (ABR) were measured for both ears of each animal before and 1, 3, 7, and 10 days after noise exposure (10 animals, $\mathrm{n}=5$ at each exposure level). Prior to measurements, animals were anesthetized with intramuscular xylazine $(10 \mathrm{mg} / \mathrm{kg})$ and ketamine $(40$ $\mathrm{mg} / \mathrm{kg}$ ), and the external ear canal and tympanic membrane were inspected under an operating microscope (Yamashita et al., 2004a). Recordings were made from differential active needle electrodes placed subcutaneously below the test ear, at the vertex, and below the contralateral ear. The sound stimulus consisted of 15-msec tone bursts, with a rise-fall time of $1 \mathrm{msec}$, at frequencies of 4,8 , and $16 \mathrm{kHz}$ and were generated by using a Fordham Audio Generator (model AG-298; Fordham Radio Supply, Hauppauge, NY). The stimuli were presented to the external auditory meatus via a closed acoustic system through a tube connected to a transducer (Beyer DT48; Beyer Dynamic, Farmingdale, NY). The sound source was calibrated by coupling with a $\mathrm{B} \& \mathrm{~K} 1 / 4$-in. microphone through a 0.6-cc rubber tube. Starting levels of 100-105 dB SPL sound intensities were decreased in $10-20 \mathrm{~dB}$ steps to near-threshold levels and then in 5-dB decrements to define threshold. One thousand twenty-four tone presentations, delivered at $10 / \mathrm{sec}$, were averaged to obtain a waveform, using a Tucker-Davis data acquisition system and a microcomputer with custom-written software. Threshold, tested separately for each ear, was defined as the lowest intensity of stimulation that yielded a repeatable waveform based on an identifiable $\mathrm{ABR}$ wave III or IV, whichever demonstrated greater sensitivity. Typically, ABR wave III was the most robust component of the guinea pig waveform, consistent with the finding of Puel et al. (1995). Thresholds were averaged across ears for each frequency in each animal.

\section{Histological Assessment of Noise-Induced Hair Cell Pathology}

Animals $(n=20)$ were euthanized under deep xylazine and ketamine anesthesia for histological study. Ten animals 
( $\mathrm{n}=5$ each at the two exposure levels) were euthanized immediately following exposure in which ABR was not assessed and another 10 animals at 10 days following exposure and the final ABR. After decapitation, the temporal bones were immediately removed and transferred into $4 \%$ paraformaldehyde in $0.1 \mathrm{M}$ phosphate-buffered saline (PBS; $\mathrm{pH} 7.4$ ). Under a dissecting microscope, the round and oval windows and the cochlear capsule near the apex were opened, followed by gentle local perfusion from the apex. The tissue was kept in fixative for $12 \mathrm{hr}$. After removal of the bony capsule and the lateral wall tissues, the modiolar core, including the organ of Corti, was removed from the temporal bone. After permeabilization with $0.3 \%$ Triton X-100 for $5 \mathrm{~min}$, the organ of Corti was stained for $\mathrm{f}$-actin with $1 \%$ rhodamine phalloidin for 40 min to outline hair cells and their stereocilia for a quantitative assessment of sensory cell loss (Raphael and Altschuler, 1991). After several washes with PBS, the organ of Corti was dissected and mounted as surface preparations. The tissues were observed under fluorescence microscopy, and the numbers of missing inner hair cells (IHC) and outer hair cells (OHC) were counted from the apex to the base in $0.19-\mathrm{mm}$ segments, as described by Yamashita et al. (2004a). Counting was begun at $2.09 \mathrm{~mm}$ from the apex, omitting the initial irregular, most apical part of the cochlear spiral. Percentages of hair cell loss in each $0.19-\mathrm{mm}$ length of tissue were plotted along the cochlear length as a cytocochleogram.

\section{Immunohistochemistry for Bcl-xL, Bak}

Immunocytochemistry was carried out in 15 animals (unexposed controls and day 1 after noise exposure at the two exposure levels, $\mathrm{n}=5$ each). ${ }^{1}$ The temporal bones were removed, transferred into $4 \%$ paraformaldehyde in PBS, locally perfused as described above, and kept in fixative overnight. After PBS rinses and removal of the bony capsule and the lateral wall tissues, the modiolar core, including the organ of Corti, was removed from the temporal bone. Tissue was incubated in blocking solution consisting of 3\% normal goat serum (Anti-Bodies Incorporated, Davis, CA) in $0.3 \%$ Triton $\mathrm{X}-100$ in PBS for $30 \mathrm{~min}$. The organ of Corti was stained with Bcl-xL antibody (1:100; Cell Signaling Technology, Beverly, MA), or Bak antibody (1:100; Cell Signaling Technology) overnight at $4^{\circ} \mathrm{C}$. Samples were washed three times in PBS and incubated for $1 \mathrm{hr}$ in a 1:200 dilution of Alexa Fluor 488-conjugated goat anti-rabbit IgG secondary antibody (Molecular Probes, Eugene, OR). Tissues were then washed three times with PBS and incubated with a 1:100 dilution of rhodamine phalloidin (Molecular Probes) for $40 \mathrm{~min}$ to outline hair cells and their stereocilia. After three PBS rinses, tissues were incubated with $5 \mu \mathrm{g} / \mathrm{ml}$ propidium iodide (PI; Molecular Probes) in PBS for 15 min to mark the nuclei of dying OHC. After three PBS rinses, the organ of Corti was dissected and mounted as a surface preparation. Immunolabeling

${ }^{1}$ In preliminary studies, Bcl-2, Bcl-xL, Bad, and Bak were assessed in these models. Bcl-2 and Bad gave little positive staining. Bcl-xL and Bak yielded immunostaining primarily on day 1 following noise exposure and none following day 3 . Thus, in the full study, only immunoreactivity on day 1 after noise exposure to Bcl-xL and Bak was assessed. was visualized with an Olympus FV-500 confocal microscope. Photomicrographs representative of the $4-\mathrm{kHz}$ region of the cochlea (primarily affected by the noise exposure) were selected from all animals. Those from each subject were then ordered based on background immunostaining (from weak to intense), and the middle photomicrograph was selected as representative for a given subject. These representative micrographs were then ordered, within each group, on the basis of background immunostaining intensity, and the photomicrograph at the midpoint of each of these groupings was selected as representative for each group of subjects. These midpoint images for each group were used to create the figures. The number of all positive immunoreactive cells for all subjects was counted from apical to basal turn and analyzed. Image scoring was conducted by an observer blind to the treatment protocol.

\section{Statistical Analysis}

All values presented in Results are mean \pm SD. Differences among the different groups were evaluated by using one-way ANOVA. The Student-Newman-Keul post hoc test was then used to evaluate the significance of specific pairs of values.

\section{RESULTS}

\section{ABR Threshold Shifts: Functional Assessment}

Figure 1A,B illustrates the ABR threshold shifts observed following noise exposure at each exposure level, over time, through 10 days. Preexposure baseline ABR thresholds did not differ between groups and were consistent with normative data previously obtained in our laboratory (not shown).

After noise exposure, maximum threshold shifts were observed on day 1 in both groups. For animals exposed to the lower intensity level (100 dB SPL, $1 \mathrm{hr}$ ), maximum threshold shifts were $27.7 \mathrm{~dB} @ 4 \mathrm{kHz}, 37.4$ dB@8 kHz, and $11.4 \mathrm{~dB} @ 16 \mathrm{kHz}$. These threshold shifts gradually decreased, and completely recovered following days 7-10 for all frequencies. Thus these animals demonstrated a TTS. Animals exposed at the higher level (120 dB SPL, for $5 \mathrm{hr}$ ) demonstrated high initial ABR threshold shifts of $40.0 \mathrm{~dB} @ 4 \mathrm{kHz}, 59.8 \mathrm{~dB} @ 8$ $\mathrm{kHz}$, and $64.8 \mathrm{~dB} @ 16 \mathrm{kHz}$ and stabilized following days 7-10 with a remaining threshold shift at all frequencies (22.6 dB@ 4 kHz, $42.5 \mathrm{~dB} @ 8 \mathrm{kHz}$, and 44.9 dB@16 kHz), similar to previous findings (Yamashita et al., 2004a). Thus, the lower noise exposure yielded a TTS model, whereas the higher level exposure yielded a PTS model of noise-exposure damage.

\section{Hair Cell Loss: Morphological Assessment}

As illustrated (Fig. 2A,B), in the animals of the TTS group (100 dB SPL, $1 \mathrm{hr}$ ), there was no significant loss of IHCs or OHCs either immediately or 10 days after noise exposure, including the $4-\mathrm{kHz}$ region of the cochlea (approximately 10-12 $\mathrm{mm}$ from the apex). However, Figure 2C,D shows, in the animals of the PTS group (120 dB SPL, $5 \mathrm{hr}$ ) immediately following 

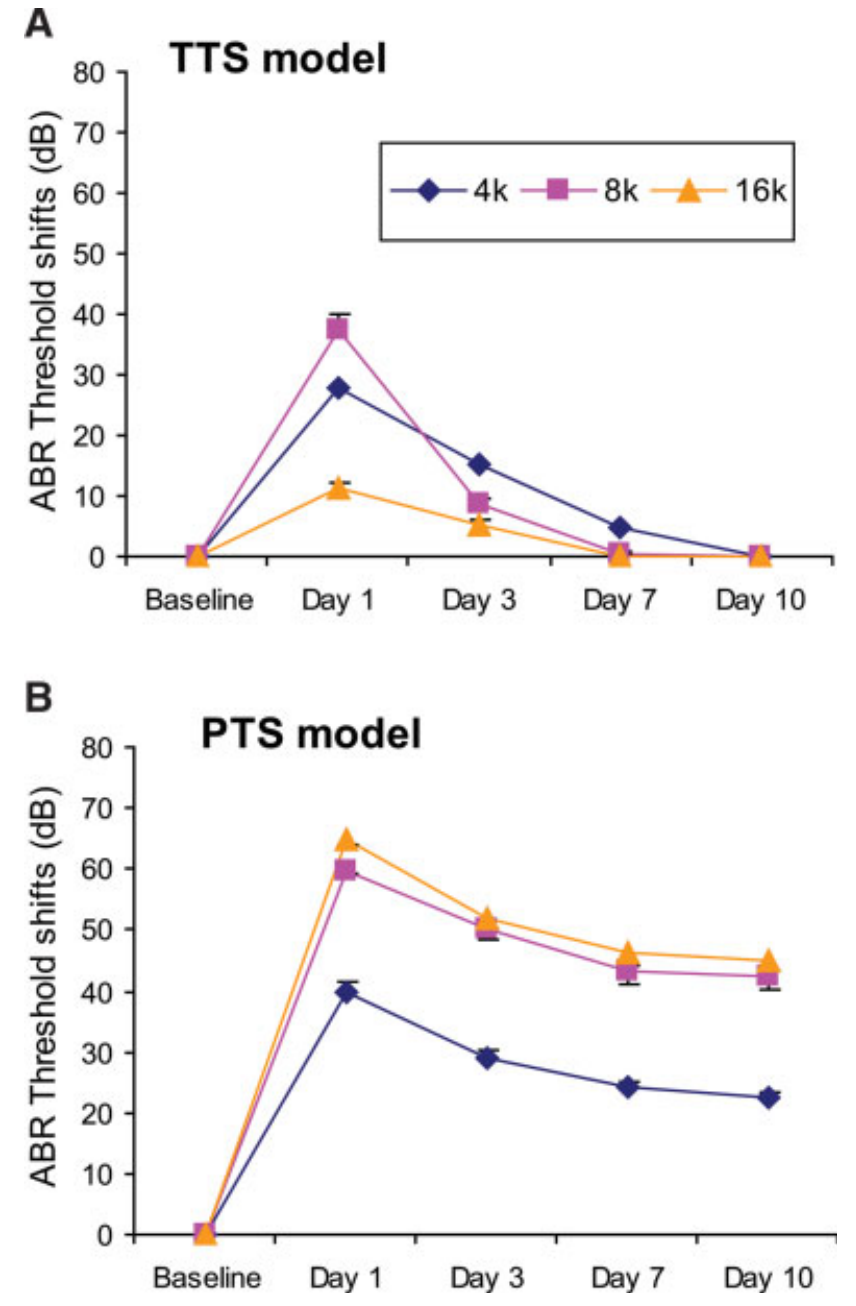

Fig. 1. Time course of ABR threshold shifts. ABR thresholds show a maximal increase 1 day after noise exposure in both groups $(A, B)$. As shown in $\mathbf{A}$, threshold shifts gradually decrease and completely recover following day 10 for all frequencies. In $\mathbf{B}$, after intense noise, after a partial recovery, threshold shifts stabilize by day 10 for all frequencies.

exposure, a clear but restricted loss of only OHCs observed in the $4-\mathrm{kHz}$ region of the cochlea (Fig. 2C). Consistent with the observed PTS, by day 10 following exposure (Fig. 2D), a restricted IHC loss was found in the cochlear region 10-12 $\mathrm{mm}$ from the apex, and OHC loss had increased in both severity and extent (apically and basally) along the basilar membrane. The damage apical to the $6-10-\mathrm{mm}$ region was due mostly to loss of OHCs in rows 2 and 3; more basally, damage was seen in all three rows. These data were consistent with previous observations (Yamashita et al., 2004a).

\section{Immunoreactivity to Bcl-xL and Bak}

Figures 3 and 4 were taken from the $4-\mathrm{kHz}$ region (10-12 $\mathrm{mm}$ from apex) representing the focus of the most heavily damaged area. The numbers of positive immunoreactive cells were counted for all turns. Staining was absent from negative control material tested without the primary antibody (not shown).

In control animals and those exposed to the TTS noise (Fig. 3A,C), normal rhodamine phalloidin staining (blue) is seen in the stereocilia and cuticular plate at the surface of the organ of Corti. In the PTS-exposed animals (Fig. 3E,F), at several points, there is both absence of rhodamine phalloidin staining (blue) and PI staining (red) indicating the loss of hair cell sterecilia, cuticular plate, and their nuclei.

Bcl-xL. After the lower intensity TTS exposure (100 dB SPL, $1 \mathrm{hr}$ ), on day 1 after noise exposure, BclxL-immunolabelled (green) OHCs were observed in row 1 at the depth of the nuclear region, consistent with cytosolic expression (Fig. 3D). Abundant immunoreactive staining was seen in both the $4-\mathrm{kHz}$ region and some in the apical region. Little Bcl-xL staining was seen in control material or in the PTS model at any site throughout the cochlea.

Bak. As shown in Figure 4F, after the more intense exposure in the PTS group, marked Bak staining (green) was observed in the cytosol of OHCs at the depth of the nuclear region, mainly restricted to row 1 . Some Bcl-xL staining was also observed. However, in contrast to the pattern of $\mathrm{Bcl}-\mathrm{xL}$ staining, positive Bak staining was restricted to the immediate region of the nucleus and limited to the $4-\mathrm{kHz}$ region. In controls and the TTS-exposure group, little Bak staining was seen.

The numbers of all positive Bcl-xL- and Bak-immunoreactive cells for all subjects were counted from apex to basal turn. The mean across subjects of each experimental group was determined for each row of hair cells. As shown in Figure 5A, Bcl-xL labeling is significantly greater in the TTS model than in control and PTS models $(P<0.01)$. Bak-immunostained cells were significantly greater in number in the PTS model than in the control and TTS-exposed material (Fig. 5B; $P<$ $0.01)$.

\section{DISCUSSION}

In this study, we demonstrated the expression of the antiapoptotic factor $\mathrm{Bcl}-\mathrm{xL}$ and the proapoptotic factor Bak following exposure to high levels of noise stimulation. However, differential expression of these genes was specifically dependent on the noise exposure intensity-duration. Bcl-xL was expressed following exposure to a sound that causes no sensory cell loss and yields a temporary change in hearing threshold with complete recovery (TTS model). Bak was expressed in response to a more intense sound that causes a permanent change in the threshold and sensory cell death (PTS model). The expression of these gene products was observed at that region of the cochlea most sensitive to the major spectral components of the sound exposure (the $4-\mathrm{kHz}$ region), localized approximately $10-12 \mathrm{~mm}$ from apex. These results indicate that $\mathrm{Bcl}-\mathrm{xL}$ may act to suppress cochlear 

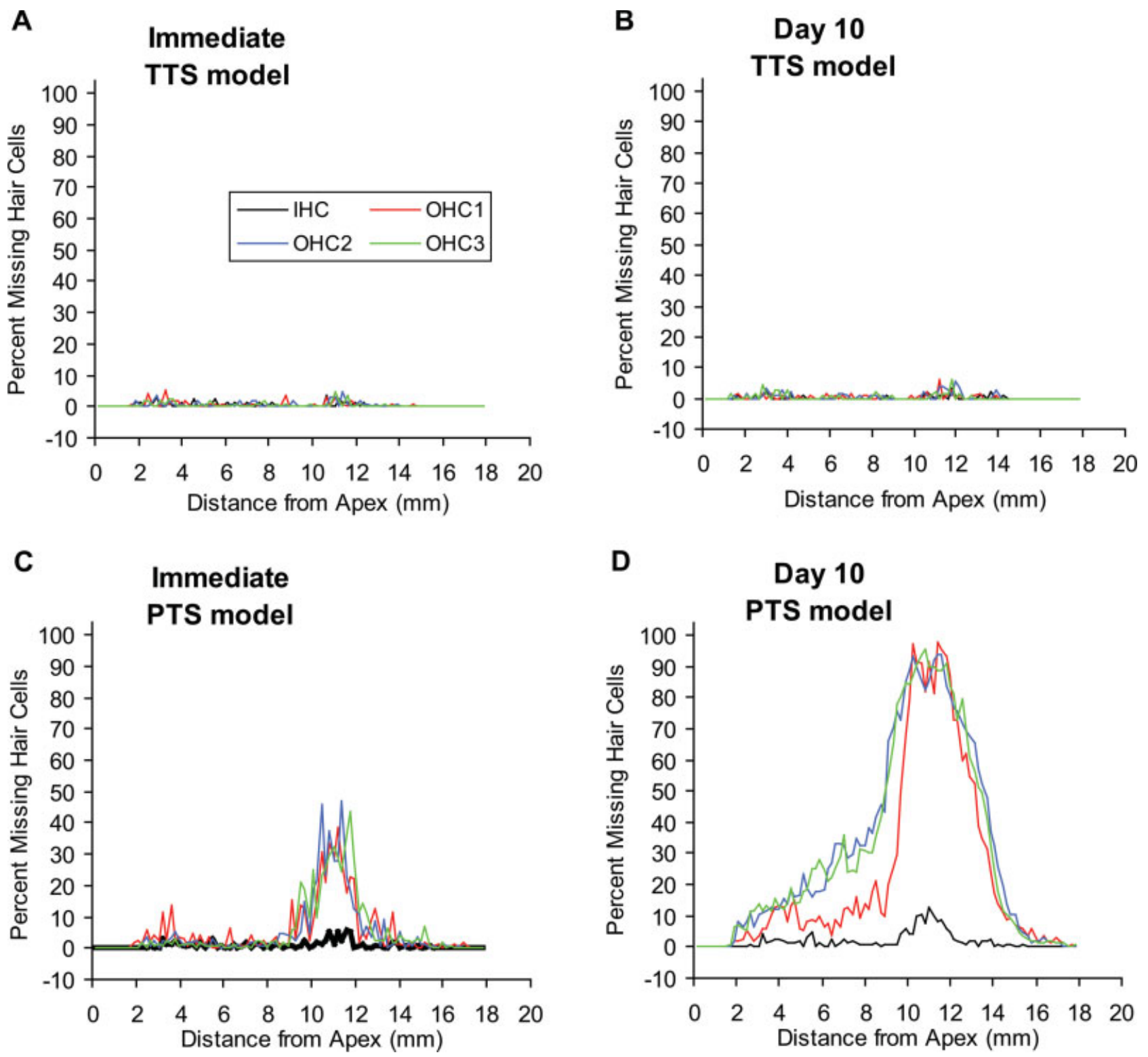

Fig. 2. Cytocochleograms, for each experimental group and time point, show the average percentage hair cell loss (IHC and OHCs row $1-3)$ of each group $(n=5)$. In the TTS model $(\mathbf{A}, \mathbf{B})$, no significant loss of IHC and OHCs is seen either immediately or on day 10 after noise exposure. In the PTS model, limited damage, located approximately 10-12 $\mathrm{mm}$ from the apex, is observed immediately after intense noise $(\mathbf{C})$, which then increased and spread apically and basally by day $10(\mathbf{D})$.

cell death induced by TTS-level noise exposure, whereas the expression of Bak, in the PTS model, may be a causative factor in induction of OHC apoptosis. These findings indicate a major role for Bcl-2 family proteins in NIHL and the survival or death of sensory hair cells following exposure to high levels of noise.

The temporary threshold shifts after noise exposure in both the TTS and PTS models are thought to arise from various reversible structural or functional changes in the cochlea, such as changes in the mechanical compliance of the basilar membrane (LePage, 1989), decreased stiffness of the hair cell stereocilia (Saunders et al., 1986), and afferent terminal excitotoxicity (Pujol and Puel, 1999). Any of these factors, if sufficiently intense, may lead to sensory cell death. Presumably, this depends on the level of noise and damage induced during or shortly following noise exposure, undoubtedly with a number of factors determining whether reversible or irreversible alterations occur. The results of this study suggest that, in the TTS model, expressions of $\mathrm{Bcl}-\mathrm{xL}$ may be a factor protecting damaged hair cells from death following exposure. One mechanism by which $\mathrm{Bcl}-\mathrm{xL}$ 

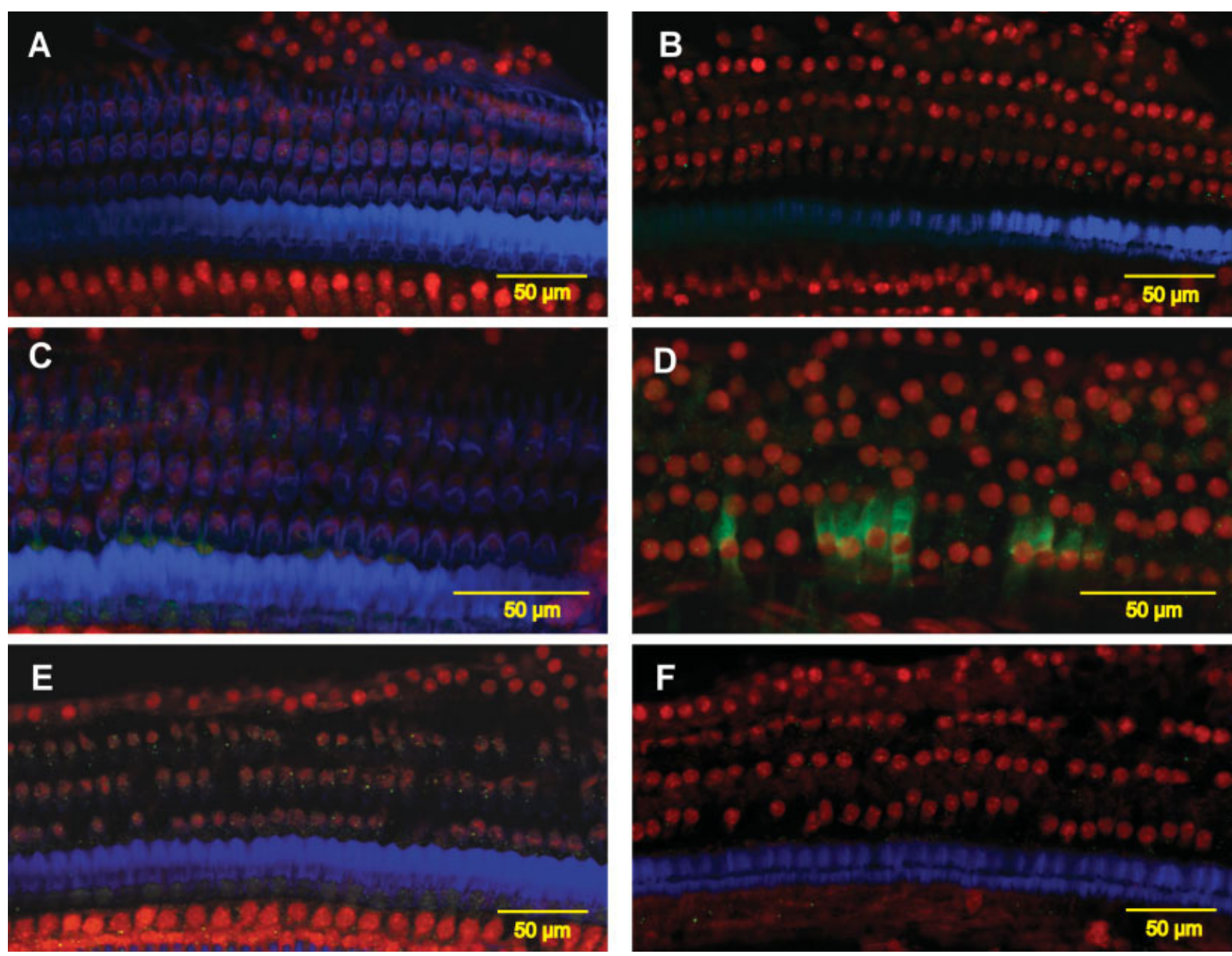

Fig. 3. Surface preparation of cochlear tissue taken day 1 after noise exposure and triply labeled for Bcl-xL (antiapoptotic; green), phalloidin (blue), and PI (red) shown at two depths from the surface of the organ of Corti: cuticular plate $(\mathbf{A}, \mathbf{C}, \mathbf{E})$ and nuclear region $(\mathbf{B}, \mathbf{D}, \mathbf{F})$. Contol results $(\mathrm{A}, \mathrm{B})$ and TTS $(\mathrm{C}, \mathrm{D})$ and PTS (E,F) results are shown. Bcl-xL immunoreactivity at the nuclear region of OHC row 1 is seen exclusively in the TTS model (D).

may mediate this survival is by blocking the release of cytochrome $c$ from the mitochondrial membrane into the cytosol, reducing excess free radical formation and allowing repair processes to affect a complete recovery. However, Bak expressed in response to greater levels of noise exposure with greater tissue effects may significantly contribute to cell death by permeabilization of the mitochondrial outer membrane and release of proteins such as cytochrome $\mathrm{c}$ that initiate apoptosis.

$\mathrm{Bcl}-\mathrm{xL}$ and Bak expression was primarily restricted to row-1 OHC, with Bcl-xL expression extending to more apical region. Morphologically, we observed that the damage apical to the $4-8-\mathrm{kHz}$ region (i.e., $6-10 \mathrm{~mm}$ from apex) reflected OHC cell death in rows 2 and 3, whereas, toward the base, damage was seen in all three rows. Because of the timing of loss of OHC (row 2 and 3 following row 1), we previously hypothesized that api- cal row 2 and 3 cell death reflects mainly necrosis induced secondary to apoptotic events in row $1 \mathrm{OHC}$ (Yamashita et al., 2004a). Given Hu et al.'s (2002) report that, 2 days after noise exposure, the numbers of fragmented and condensed (apoptotic) nuclei are dramatically shifted from the $4-\mathrm{kHz}$ region toward the basal part of the cochlea, we suggest that it is the apical expression of $\mathrm{Bcl}-\mathrm{xL}$, observed in this study, that significantly limits the spread of cell death from the $4-\mathrm{kHz}$ region to lower (apical) regions of the cochlea, particularly in row $1 \mathrm{OHC}$.

Support for the potential role of $\mathrm{Bcl}-2$ proteins in noise-induced cell survival and death is also based on previously reported findings that calcineurin activity is up-regulated in hair cells $24 \mathrm{hr}$ after noise exposure (Minami et al., 2004). Calcineurin expression, which is controlled by $\left[\mathrm{Ca}^{2+}\right]_{\mathrm{i}}$ and calmodulin, activates cell 

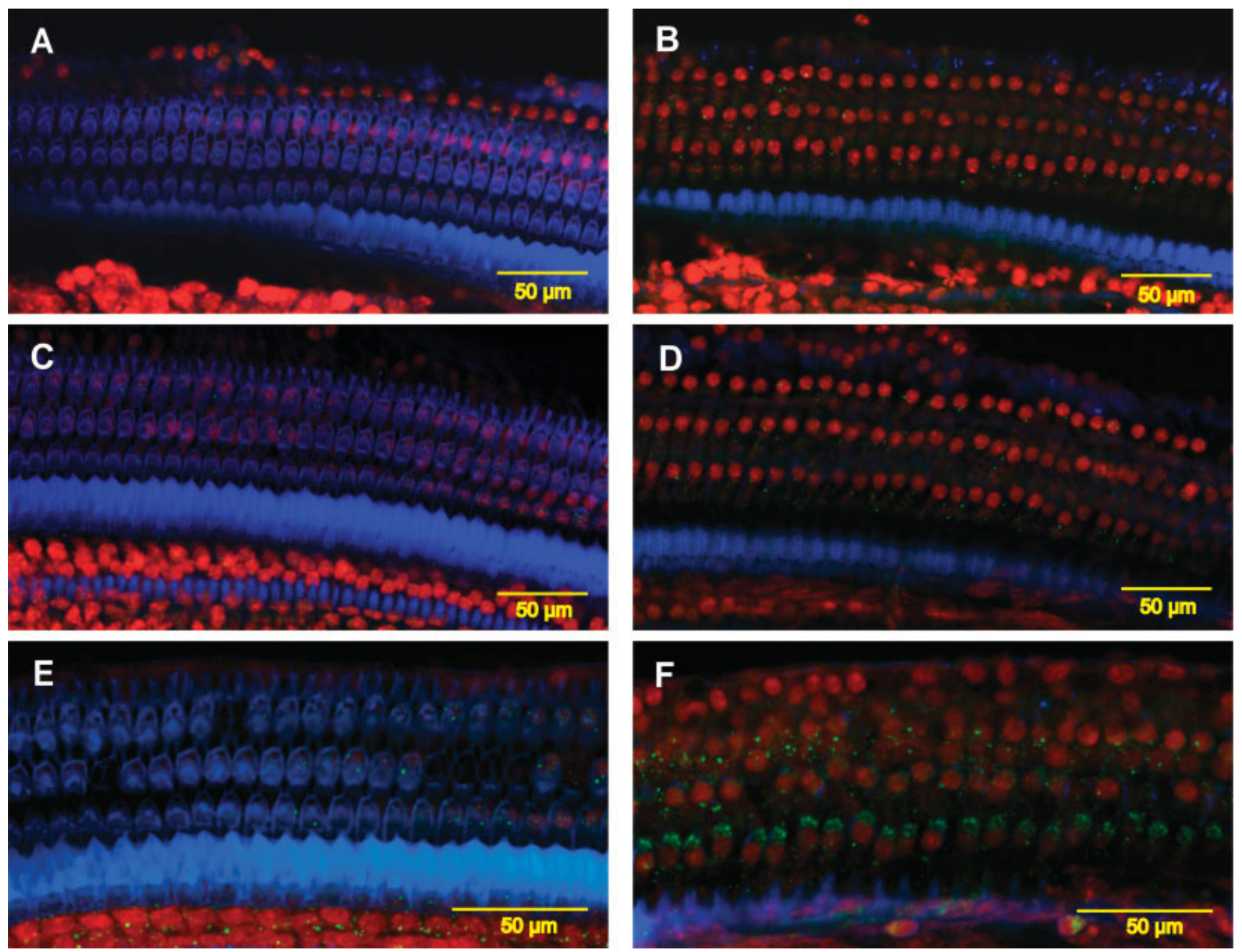

Fig. 4. Surface preparation of cochlear tissue taken 1 day after noise exposure and triply labeled for Bak (proapoptotic; green), phalloidin (blue), and PI (red) shown at two depths of the organ of Corti: cuticular plate $(\mathbf{A}, \mathbf{C}, \mathbf{E})$ and nuclear region $(\mathbf{B}, \mathbf{D}, \mathbf{F})$. Contol results $(\mathrm{A}, \mathrm{B})$ and TTS $(\mathrm{C}, \mathrm{D})$ and PTS $(\mathrm{E}, \mathrm{F})$ results are shown. Bak immunoreactivity at the nuclear region of $\mathrm{OHC}$ row 1 is seen exclusively in the PTS model (F).

death pathways by dephosphorylating the Bcl-2 family protein Bad (Wang et al., 1999) and inactivating the antiapoptotic Bcl-2 (Erin et al., 2003). Other studies have shown that, with the permeabilization of the outer mitochondrial membrane by the activation, translocation, and oligomerization of multidomain Bcl-2 family proteins, EndoG, an apoptotic nuclease belonging to a family of $\mathrm{Mg}^{2+}$-dependent nucleases (Miller et al., 1999), is released (Arnoult et al., 2003; Er et al., 2006). Recently Yamashita et al. (2004b) demonstrated that EndoG is expressed in the inner ear $24 \mathrm{hr}$ following noise exposure and translocates to the nucleus after noise exposure, where it induced caspase-independent apoptotic cell death. These new data are consistent with a key role of $\mathrm{Bcl}-2$ genes in the response of the inner ear to acoustic trauma.
The findings of this paper support many recent studies showing that overexpression of Bcl-2 family proteins can reduce neuronal cell death, including ischemic brain injury, in animal models. Defective herpes simplex viral (HSV) vectors were utilized to induce Bcl-2 overexpression, which was protective against excitotoxic insults in vitro and in vivo (Lawrence et al., 1996). Bcl2-based gene therapy was effective even when given after the onset of injury (Dumas et al., 2000), and Zhao et al. (2003) demonstrated Bcl-2 gene transfer to the margin of infarcts, providing protection from ischemia. This protection was accompanied by reduced cytochrome $c$ translocation to the cytosol and reduced activation of caspase-3. Finally, Cao et al. (2002) reported that $\mathrm{Bcl}-\mathrm{xL}$ inhibited staurosporine-induced apoptosis in primary cultured neocortical neurons and reduced neu- 
A

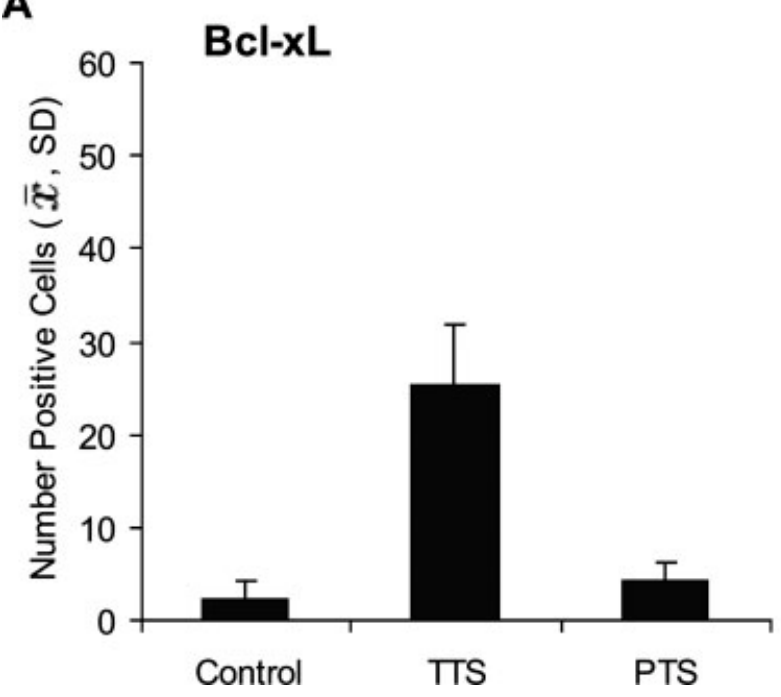

B

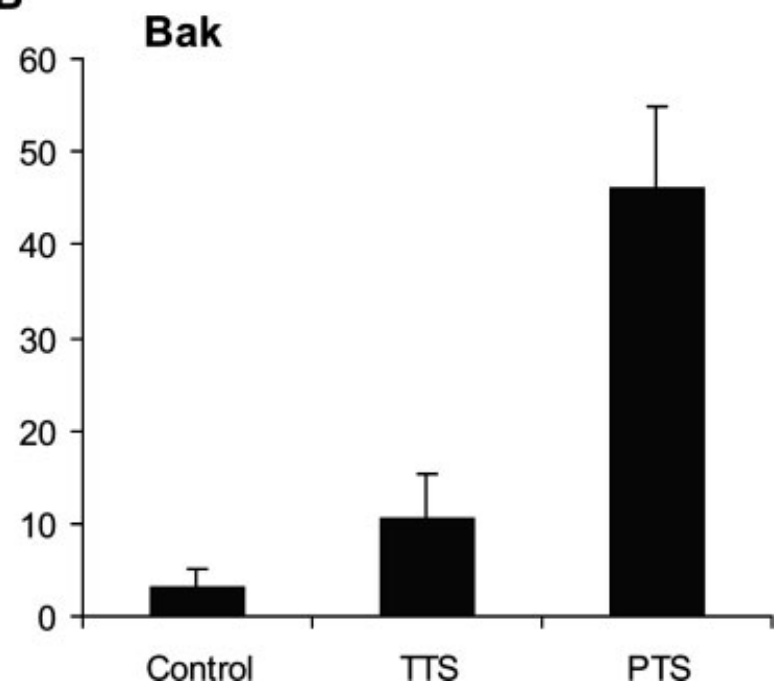

Fig. 5. Statistical analysis for the total number of Bcl-xL- and Bak-immunopositive hair cells. A: Significant positive staining of $\mathrm{Bcl}-\mathrm{xL}$ in the TTS model compared with control and PTS subjects $(P<0.01)$. B: Bak immunostaining was significantly increased in the PTS model $(P<0.01)$.

ronal death resulting from transient focal ischemia in the intact brain.

Gene and protein therapy using antiapoptotic Bcl-2 family members may provide significant protection against neural injury, including sensory cells of the inner ear in association with NIHL. We have recently demonstrated that both pre- and postnoise exposure treatment with a combination of antioxidants (Yamashita et al., 2005) can be effective in significantly reducing NIHL. This strategy holds promise for reducing this important and costly disorder. However, with recent work showing a caspase-independent, apoptotic, EndoG-driven cell death pathway in NIHL (Yamashita et al., 2004b), and a role for Bcl-2 family genes in modulating noise-induced hair cell loss (which may, in part, reflect a noise-induced calcineurin up-regulation), it is clear that many aspects of the biochemical pathways involved in NIHL remain to be identified and analyzed. With each additional insight, we should define new and improved interventions that may be translated from the laboratory to clinical application and, with that, significantly reduce this important cause of hearing impairment.

\section{REFERENCES}

Adams JM, Cory S. 1998. The Bcl-2 protein family: arbiters of cell survival. Science 281:1322-1326.

Alam SA, Ikeda K, Oshima T, Suzuki M, Kawase T, Kikuchi T, Takasaka T. 2000. Cisplatin-induced apoptotic cell death in Mongolian gerbil cochlea. Hear Res 141:28-38.

Alam SA, Oshima T, Suzuki M, Kawase T, Takasaka T, Ikeda K. 2001. The expression of apoptosis-related proteins in the aged cochlea of Mongolian gerbils. Laryngoscope 111:528-534.

Arnoult D, Gaume B, Karbowski M, Sharpe JC, Cecconi F, Youle RJ. 2003. Mitochondrial release of AIF and EndoG requires caspase activa- tion downstream of Bax/Bak-mediated permeabilization. EMBO J 22:4385-4399.

Asoh S, Ohsawa I, Mori T, Katsura K, Hirade T, Katayama Y, Kimura M, Ozaki D, Yamagata K, Ohta S. 2002. Protection against ischemic brain injury by protein therapeutics. Proc Natl Acad Sci U S A 99:17107-17112.

Cao G, Pei W, Ge H, Liang Q, Luo Y, Sharp FR, Lu A, Ran R, Graham SH, Chen J. 2002. In vivo delivery of BCL-XL fusion protein containing the TAT protein transduction domain protects against ischemic brain injury and neuronal apoptosis. J Neurosci 22:5423-5431.

Coling DE, Yu KC, Somand D, Satar B, Bai U, Huang TT, Seidman MD, Epstein CJ, Mhatre AN, Lalwani AK. 2003. Effect of SOD1 overexpression on age- and noise-related hearing loss. Free Radic Biol Med 34:873-880.

Cunningham LL, Matsui JI, Warchol ME, Rubel EW. 2004. Overexpression of $\mathrm{Bcl}-2$ prevents neomycin-induced hair cell death and caspase- 9 activation in the adult mouse utricle in vitro. J Neurobiol 60:89-100.

Dumas TC, McLaughlin JR, Ho DY, Lawrence MS, Sapolsky RM. 2000. Gene therapies that enhance hippocampal neuron survival after an excitotoxic insult are not equivalent in their ability to maintain synaptic transmission, Exp Neurol 166:180-189.

Er E, Oliver L, Cartron PF, Juin P, Manon S, Vallette FM. 2006. Mitochondria as the target of the pro-apoptotic protein Bax. Biochim Biophys Acta 1757:1301-1311.

Erin N, Bronson SK, Billingsley ML. 2003. Calcium-dependent interaction of calcineurin with Bcl-2 in neuronal tissue. Neuroscience 117:541-555.

Ganju N, Eastman A. 2002. Bcl-X(L) and calyculin A prevent translocation of Bax to mitochondria during apoptosis. Biochem Biophys Res Commun 291:1258-1264.

Green DR, Kroemer G. 2004. The pathophysiology of mitochondrial cell death. Science 305:626-629.

Henderson D, Bielefeld EC, Harris KC, Hu BH. 2006. The role of oxidative stress in noise-induced hearing loss [review]. Ear Hear 27:1-19. 
Hu BH, Henderson D, Nicotera TM. 2002. Involvement of apoptosis in progression of cochlear lesion following exposure to intense noise. Hear Res 166:62-71.

Hu BH, Henderson D, Nicotera TM. 2006. Extremely rapid induction of outer hair cell apoptosis in the chinchilla cochlea following exposure to impulse noise. Hear Res 211:16-25.

Ishii N, Wanaka A, Ohno K, Matsumoto K, Eguchi Y, Mori T, Tsujimoto Y, Tohyama M. 1996. Localization of bcl-2, bax, and bcl-x mRNAs in the developing inner ear of the mouse. Brain Res 726:123128.

Klee M, Pimentel-Munoz FX. 2005. Bcl-XL specifically activates Bak to induce swelling and restructuring of the endoplasmic reticulum. J Cell Biol 168:723-724.

Lang H, Schulte BA, Zhou D, Smythe N, Spicer SS, Schmiedt RA. 2006. Nuclear factor kappaB deficiency is associated with auditory nerve degeneration and increased noise-induced hearing loss. J Neurosci 26:3541-3550.

Lawrence MS, Ho DY, Sun GH, Steinberg GK, Sapolsky RM. 1996. Overexpression of $\mathrm{Bcl}-2$ with herpes simplex virus vectors protects CNS neurons against neurological insults in vitro and in vivo. J Neurosci 16:486-496.

LePage EL. 1989. Functional role of the olivo-cochlear bundle: a motor unit control system in the mammalian cochlea. Hear Res 38:177-198.

Miller MD, Cai J, Krause KL. 1999. The active site of Serratia endonuclease contains a conserved magnesium-water cluster. J Mol Biol 288:975-987.

Minami SB, Yamashita D, Schacht J, Miller JM. 2004. Calcineurin activation contributes to noise-induced hearing loss. J Neurosci Res 78:383-392.

Nicotera TM, Hu BH, Henderson D. 2003. The caspase pathway in noise-induced apoptosis of the chinchilla cochlea. J Assoc Res Otolaryngol 4:466-477.

Niu X, Shao R, Canlon B. 2003. Suppression of apoptosis occurs in the cochlea by sound conditioning. Neuroreport 14:1025-1029.

Ohinata Y, Miller JM, Schacht J. 2003. Protection from noise-induced lipid peroxidation and hair cell loss in the cochlea. Brain Res 966:265273.

Ohlemiller KK, McFadden SL, Ding DL, Lear PM, Ho YS. 2000. Targeted mutation of the gene for cellular glutathione peroxidase (Gpx1) increases noise-induced hearing loss in mice. J Assoc Res Otolaryngol 1:243-254.

Ouyang YB, Giffard RG. 2004. Cellular neuroprotective mechanisms in cerebral ischemia: $\mathrm{Bcl}-2$ family proteins and protection of mitochondrial function. Cell Calcium 36:303-311.

Puel JL, Saffiedine S, Gervais d'Aldin C, Eybalin M, Pujol R. 1995. Synaptic regeneration and functional recovery after excitotoxic injury in the guinea pig cochlea. C R Acad Sci III 318:67-75.
Pujol R, Puel JL. 1999. Excitotoxicity, synaptic repair, and functional recovery in the mammalian cochlea: a review of recent findings. Ann $\mathrm{N}$ Y Acad Sci 884:249-254.

Raphael Y, Altschuler RA. 1991. Reorganization of cytoskeletal and junctional proteins during cochlear hair cell degeneration. Cell Motil Cytoskel 18:215-27.

Saunders JC, Canlon B, Flock A. 1986. Changes in stereocilia micromechanics following overstimulation in metabolically blocked hair cells. Hear Res 24:217-225.

Scorrano L, Oakes SA, Opferman JT, Cheng EH, Sorcinelli MD, Pozzan T, Korsmeyer SJ. 2003. BAX and BAK regulation of endoplasmic reticulum $\mathrm{Ca}^{2+}$ : a control point for apoptosis. Science 300:135-139.

Tsujimoto Y, Shimizu S. 2000a. Bcl-2 family: life-or-death switch. FEBS Lett 466:6-10.

Tsujimoto Y, Shimizu S. 2000b. VDAC regulation by the Bcl-2 family of proteins. Cell Death Differ 7:1174-1181.

Van Campen LE, Murphy WJ, Franks JR, Mathias PI, Toraason MA. 2002. Oxidative DNA damage is associated with intense noise exposure in the rat. Hear Res 164:29-38.

Vicente-Torres MA, Schacht J. 2006. A BAD link to mitochondrial cell death in the cochlea of mice with noise-induced hearing loss. J Neurosci Res 83:1564-1572.

Vieira HL, Haouz D, El Hamel C, Jacotot E, Belzac A-S, Brenner C, Kroemer G. 2000. Permeabilization of the mitochondrial inner membrane during apoptosis: impact of the adenine nucleotide translocator. Cell Death Differ 7:1146-1154.

Wang HG, Pathan N, Ethell IM, Krajewski S, Yamaguchi Y, Shibasaki F, McKeon F, Bobo T, Franke TF, Reed JC. 1999. $\mathrm{Ca}^{2+}$-induced apoptosis through calcineurin dephosphorylation of BAD. Science 284:339-343.

Wang J, Van De Water TR, Bonny C, de Ribaupierre F, Puel JL, Zine A. 2003. A peptide inhibitor of c-Jun N-terminal kinase protects against both aminoglycoside and acoustic trauma-induced auditory hair cell death and hearing loss. J Neurosci 3:8596-8607.

Yamashita D, Jiang HY, Schacht J, Miller JM. 2004a. Delayed production of free radicals following noise exposure. Brain Res 1019:201-209.

Yamashita D, Miller JM, Jiang HY, Minami SB, Schacht J. 2004b. AIF and EndoG in noise-induced hearing loss. Neuroreport 15:2719-2722.

Yamashita D, Jiang H-Y, Le Prell CG, Schacht J, Miller JM. 2005. Postexposure treatment attenuates noise-induced hearing loss. Neuroscience 134:633-642.

Yang WP, Henderson D, Hu BH, Nicotera TM. 2004. Quantitative analysis of apoptotic and necrotic outer hair cells after exposure to different levels of continuous noise. Hear Res 196:69-76.

Zhao H, Yenari MA, Cheng D, Sapolsky RM, Steinberg GK. 2003. Bcl-2 overexpression protects against neuron loss within the ischemic margin following experimental stroke and inhibits cytochrome c translocation and caspase-3 activity. J Neurochem 85:1026-1036. 